\title{
Necesidades de formación académica y capacitación profesional para los maestros unidocentes en el Sistema Educativo Costarricense
}

\section{Needs of academic and professional training for one- room school teachers of the Costa Rican Educational System}

\author{
Sabrina Cantillo Gamboa ${ }^{1}$ \\ Ministerio de Educación Pública \\ San José, Costa Rica \\ skang13@hotmail.com \\ Johanna Cordero Soto ${ }^{2}$ \\ Liceo Franco Costarricense \\ cs@yahoo.com \\ Dennis Estrada Blanco ${ }^{3}$ \\ Liceo Franco Costarricense \\ destradablanco@gmail.com
}

Recibido 02 octubre 2011 * Aceptado 05 octubre 2011 * Corregido 27 noviembre 2011

\begin{abstract}
Resumen. El presente artículo aborda, desde la óptica de los maestros unidocentes pertenecientes a las diferentes Direcciones Regionales de Costa Rica, la formación profesional y la capacitación que han recibido, así como las demandas que plantean e indican como esenciales de solventar para una mejor gestión y labor pedagógica. La investigación realizada se ubica dentro del enfoque cuantitativo, se considera de carácter descriptivo y con diseño no experimental. El estudio recopila y sistematiza información de los maestros unidocentes pertenecientes a las diferentes Direcciones Regionales de Costa Rica, con respecto de la formación y capacitación que han recibido, así como las demandas que plantean e indican como esenciales de solventar para una mejor gestión y labor pedagógica. Entre los principales hallazgos se encuentra el hecho de que los docentes expresan sentirse insatisfechos con la formación académica recibida, así como se evidencia un vacío en lo que corresponde a la formación del maestro unidocente. Se manifiesta \footnotetext{
con énfasis en la Enseñanza del Francés. Actualmente labora como docente en el Liceo de Pavas. con énfasis en la Enseñanza del Francés. Actualmente labora como Asistente de Vida Estudiantil en el Liceo Franco Costarricense. Además, labora como docente en la Universidad La Salle. Educación con énfasis en Administración de la Educación. Actualmente labora como Asistente de Dirección de Centro Educativo en el Liceo Franco Costarricense.
}

${ }^{1}$ Licenciada en Ciencias de la Educación con énfasis en Administración Educativa y Bachiller en Ciencias de la Educación

${ }^{2}$ Licenciada en Ciencias de la Educación con énfasis en Administración Educativa y Bachiller en Ciencias de la Educación

${ }^{3}$ Licenciada en Ciencias de la Educación con énfasis en Administración Educativa y Licenciatura en Ciencias de la
\end{abstract}

Número publicado el 20 de diciembre de 2011 URL: http://revistadigital.eae.fcs.ucr.ac.crl 
Revista Gestión de la Educación, Vol.1, º2, pp.67-106, ISSN 2215-2288, julio-diciembre, 2011

también la necesidad de programas de capacitación en el campo. Importante rescatar que este grupo profesional declara interés por actualizarse y adquirir nuevos conocimientos para un adecuado desempeño profesional. La investigación también reveló que los maestros unidocentes deben formarse especialmente en el uso de las Tecnologías de la Información y la Comunicación (TICs) y la Internet, y poder de esta forma, responder con mayor eficiencia desde su gestión, en especial cuando las escuelas se encuentran en áreas rurales de difícil acceso y muy distanciadas unas de otras. Con este estudio se logró inferir la necesidad de ofrecer espacios formativos especializados en unidocencia, tanto en entes privados como públicos de la educación.

Palabras clave. Unidocentes, organización, formación, capacitación, gestión de centros unidocentes, administración de la educación.

Abstract. This article refers to a research that addresses from the perspective of one-room school teachers belonging to different Regional Educational Directions in Costa Rica, the training, and demands stated as essential to solve for better management and educational work. This research has a descriptive and non-experimental design in a quantitative approach. The study collects and organizes information from one-room school teachers belonging to the different Regional Educational Directions in Costa Rica, according to the training they have received, and demands stated as essential for a better management and educational work. Among the key findings is the fact that teachers reported feeling dissatisfied with the academic training received; as well as, evidence of a gap in teacher training to one-room school teacher. It is also expressed in the need for training programs in this field. This professional group expresses interest in updating, upgrading and acquiring new knowledge for a proper professional performance. The research also revealed that these teachers should be specially trained in the use of Information and Communication Technology (ICT), and the Internet in order to answer with a higher, efficiency in their work, especially, when these schools are in remote rural areas, and far away from each other. In this study, it was possible to infer the need to provide specialized training for one-room teachers in both private and public educational entities.

Key words. Single-teacher, one-room school teachers, one-teacher, organization, training, oneroom school management, educational administration, educational management.

\section{Introducción}

La educación costarricense posee muchas modalidades educativas, una de esas son las organizaciones educativas unidocentes ${ }^{4}$, las cuales se caracterizan por estar localizadas generalmente en zona rural, a cargo de un docente, quien imparte todos los grados en forma simultánea y además, se hace cargo de las funciones administrativas de la institución educativa.

\footnotetext{
4 Las escuelas unidocentes, deben su nombre a que son asumidas por un solo maestro unidocente, en algunos sistemas educativos también, se les denomina escuelas multigrado. El maestro unidocente tiene a cargo los seis grados que se imparten en la educación primaria, posee como máximo 30 estudiantes, y a su vez asume la parte administrativa del centro educativo, se ubican en zonas rurales. Esta es la gran diferencia que tienen en relación con las otras instituciones educativas en el sistema educativo costarricense.
}

Número publicado el 20 de diciembre de 2011 URL: http://revistadigital.eae.fcs.ucr.ac.crl 
Revista Gestión de la Educación, Vol.1, №2, pp.67-106, ISSN 2215-2288, julio-diciembre, 2011

Algunos de los problemas más relevantes en las organizaciones educativas unidocentes son: el poco acceso a las nuevas tecnologías, dado que no todas las escuelas cuentan con conexión a la Internet o poseen equipo tecnológico; así como problemas de infraestructura y económicos, entre otros.

El Manual Descriptivo de Clases de Puestos Docentes del Régimen de Servicio Civil en Costa Rica, describe la naturaleza del trabajo del Profesor de Enseñanza Unidocente (I y II ciclos) de la siguiente forma: "planeamiento y preparación de las lecciones, desarrollo de los programas de la Enseñanza General Básica y dirección de una organización educativa rural de I y II ciclos con una matrícula de hasta 50 alumnos". (Actualmente el número de estudiantes no puede ser mayor a 30, según resolución DG097-2009 de la Dirección General de Servicio Civil).

Las funciones que realizan estos profesionales se basan fundamentalmente en labores de planificación, orientación, gestión u otra actividad íntimamente relacionada con el desarrollo del currículo de una organización educativa unidocente, es decir, realizan labores de docencia y también administrativas; por lo tanto, al profesional unidocente, en su función de educador y como responsable de la gestión, le demanda conocimientos y formación académica en ambas áreas. Al respecto, Delgado (2005) comenta que:

La labor del unidocente no es fácil ya que debe ser: docente, administrador, conserje, coordinador de grupos de apoyo, evaluador, entre otras funciones, lo que hace imposible solucionar todo satisfactoriamente si no se recurre a estrategias de integración de la comunidad educativa al quehacer educativo. (p. 8)

Conforme a lo anterior, se puede inferir el tipo de formación académica ${ }^{5}$ que deben poseer los maestros unidocentes y la capacitación profesional ${ }^{6}$ que necesitan recibir para actualizarse en materia pedagógica y de administración de la educación. Por consiguiente, es importante focalizar qué causas impiden el buen quehacer del maestro unidocente.

5 Formación académica se refiere a los estudios universitarios cursados, en este caso por los educadores y las educadoras para obtener su grado académico extendido por una universidad y poderse desempeñar en el sistema educativo costarricense como educadores. 


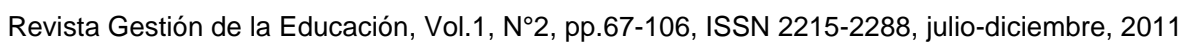

De esta manera, es esencial que organizaciones educativas como son las organizaciones educativas unidocentes posean no solo los recursos necesarios, sino también, profesionales, con la formación académica idónea para ofrecer una educación de calidad donde el ser humano desarrolle sus potencialidades de acuerdo con sus capacidades.

Para responder satisfactoriamente a todas las funciones de una organización educativa, se requiere de una variedad de habilidades y destrezas profesionales y personales bajo el mando de un profesional en el campo de la administración de la educación, comprometido y conocedor de la labor por realizar dentro y fuera de la organización educativa.

La investigación se planteó los siguientes objetivos:

Objetivo general

Analizar las necesidades de formación y capacitación de los (as) maestros (as) unidocentes de las Direcciones Regionales de Educación del Sistema Educativo Costarricense para responder a los requerimientos de la educación costarricense.

Objetivos específicos

1. Determinar la formación académica que tienen los (as) maestros (as) unidocentes de las Direcciones Regionales de Educación del Sistema Educativo Costarricense.

2. Identificar la capacitación profesional recibida por los (as) maestros (as) unidocentes de las Direcciones Regionales de Educación del Sistema Educativo Costarricense.

3. Describir el uso que hacen los (as) maestros (as) unidocentes de las Tecnologías de la Información y de la Comunicación y de la Internet.

6 Formación profesional es la que se recibe en el ejercicio del docente para el mejoramiento de su desarrollo profesional, por lo general es impartida por el Ministerio de Educación Pública o Instituciones especializadas

Número publicado el 20 de diciembre de 2011 URL: http://revistadigital.eae.fcs.ucr.ac.crl 
Revista Gestión de la Educación, Vol.1, N², pp.67-106, ISSN 2215-2288, julio-diciembre, 2011

4. Determinar los indicadores en las demandas de formación académica de los (as) maestros (as) unidocentes para su desempeño laboral que requiere el Sistema Educativo Costarricense.

5. Determinar los indicadores en las demandas de capacitación de los (as) maestros (as) unidocentes para su desempeño laboral según las necesidades del Sistema Educativo Costarricense.

6. Definir soluciones para las necesidades de formación y capacitación de los (as) maestros (as) unidocentes.

El aporte que ofrece este estudio no se limita a precisar las necesidades de formación profesional y de capacitación de los maestros unidocentes, sino que pretende resaltar su función, brindando la posibilidad de capacitarse en el área de la administración de la educación, conocimiento que ayudará a alcanzar los fines educativos y brindar una verdadera educación de calidad.

\section{Referente teórico}

\section{La gestión de la educación}

El término "gestión" en materia de educación es relativamente reciente. Esta actividad se vive a diario dentro de las tareas que se ejercen en las diferentes organizaciones educativas, entre ellas, la gestión del recurso humano, económico, del currículo y de la infraestructura. La gestión se enfoca hacia la aplicación del conocimiento existente para lograr el cumplimiento de los objetivos organizacionales en sus niveles operativos.

en el campo.

Número publicado el 20 de diciembre de 2011 URL: http://revistadigital.eae.fcs.ucr.ac.crl 


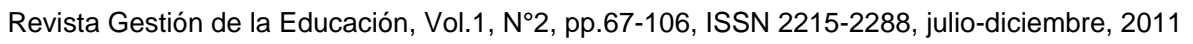

El sistema de gestión para otros va más allá de la organización, a criterio de ISO 9004 (2000), toma en cuenta la capacidad de operar una organización con éxito, para lo que se requiere gestionarla en forma sistemática. El sistema de gestión debe ser diseñado para mejorar continuamente la eficacia y eficiencia del desempeño de la organización, tomando en cuenta las necesidades de las partes interesadas según los criterios de calidad.

La gestión debe seguir una serie de pasos para obtener resultados positivos dentro de una organización. Para Chiavenato (2005) este proceso se relaciona con la planificación, organización, dirección y control de los recursos (humanos, financieros, materiales, tecnológicos) de la organización, con el fin de obtener el máximo beneficio posible; esta ayuda puede ser económica o social, dependiendo esto de los fines que persiga la organización.

La gestión de la educación persigue la satisfacción de las necesidades de los estudiantes, de la comunidad donde se desenvuelve, de los colaboradores de la organización educativa, así como de la sociedad costarricense. El administrador, mediante su gestión tiene la responsabilidad de ofrecer un servicio de calidad, el cual pueda responder a las exigencias de un mundo competitivo e innovador. De manera que se requiere de actores comprometidos con el desarrollo del país, y la forma de adquirir este compromiso es por medio de la educación, pero de una educación de calidad. El administrador y la administradora de la educación deben encontrarse a la vanguardia de las innovaciones tecnológicas para afrontar las exigencias del Estado costarricense. "La tecnología y la globalización están revolucionando la forma de enseñar y aprender. Las instituciones educacionales y los educadores deben estar preparados para administrar el cambio y obtener los mayores beneficios de estos desarrollos" (Lepeley, 2003, p. 44). 


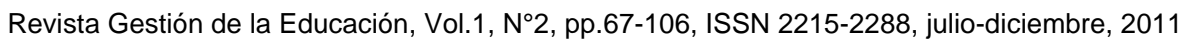

De otro modo, la gestión debe considerar los recursos reales que tenga el administrador para solventar las necesidades prioritarias de la organización educativa. Para conocerlas deberán guiar la elaboración de un plan y los proyectos, realizar la gestión para garantizar el desarrollo apropiado de la organización. Son desempeños importantes en este ámbito: el diagnóstico, las políticas institucionales, la elaboración del plan y de los proyectos, la toma de decisiones, la delegación de funciones, la sinergia, el cambio, la gestión de los recursos, el uso del tiempo, respeto y aplicación de las normas legales y reglamentarias (Bernal, 1997).

Es de suma importancia que exista la integración en la organización educativa con la comunidad y los entes gubernamentales disponibles, para así crear enlaces y estrategias que mejoren el desempeño de la organización educativa. Por más sencilla que sea esta, los enlaces con otras organizaciones fomentan el cambio y la competencia, siempre teniendo en cuenta las necesidades y los intereses de la población a cargo.

Según Correa de Molina (2004) la gestión desde la calidad es considerada como:

La gestión de la calidad es considerada por la nueva norma como un proceso que parte de unas necesidades manifestadas por los clientes, sobre los que se trabaja, para la obtención de procesos y productos, mediante la aplicación de los principios de mejora continua. (p. 80)

Desde esa perspectiva, la dirección de la organización educativa es la responsable de su implementación y mantenimiento, además, de lograr los recursos requeridos con el liderazgo necesario para su logro. La gestión de la educación debe considerarse un proceso continuo, que exige una evaluación constante para los cambios o las innovaciones pertinentes en el proceso o realización de proyectos. El líder debe ser un ente observador y acompañar el camino que toma la organización educativa, motivando y realizando las mejoras pertinentes para el éxito de las metas establecidas. 
Revista Gestión de la Educación, Vol.1, №2, pp.67-106, ISSN 2215-2288, julio-diciembre, 2011

\section{Gestión de centros unidocentes}

La gestión en la organización educativa unidocente posee responsabilidades y tareas variadas dentro y fuera del aula. Como toda organización educativa debe cumplir con funciones tanto docentes como administrativas. En este caso es necesario señalar que el maestro unidocente ejecuta ambas funciones y otra serie de tareas que en otras instituciones estarían asignadas a otra clase de puesto.

Lo anterior hace que la labor de un maestro unidocente sea compleja y variada, con el inconveniente de la falta de preparación académica para desempeñarse correctamente; carecen de conocimientos didácticos para atender varios grupos a la vez, así como de conocimientos en administración y legislación educativa.

Es importante señalar, que la gestión en una organización educativa "consiste básicamente en el conjunto de acciones que realizan ciertas personas en las organizaciones, para facilitar que estas funcionen y se logren los objetivos en condiciones adecuadas" (Alvarado y Maya, 2009, p. 118). Lo anterior hace pensar, que el desempeño que realizan estos docentes depende del grado de responsabilidad, vocación y compromiso de cada uno.

El modelo de gestión de una organización educativa está intrínsecamente ligado al tipo de liderazgo que ejerza el docente, de sus habilidades, compromiso, creatividad, responsabilidad y por supuesto de la formación académica. Depende también, de las características de la comunidad en la cual se encuentra inmersa la escuela.

Las organizaciones educativas unidocentes, a pesar de las limitaciones y la escasez, tienen que hacer los esfuerzos para brindarles a los niños y niñas de esa población rural, las herramientas para desenvolverse mejor ante los desafíos actuales.

En el caso específico de la organización educativa unidocente, algunas labores se realizan con ayuda de los padres y las madres de familia, miembros de la comunidad educativa sean asociaciones, municipalidad u otras. Por consiguiente, la organización de la escuela, la instauración de un buen ambiente, la distribución del tiempo, la formulación de proyectos y el trabajo con los padres de familia, forman parte de la gestión que el maestro unidocente tiene a su cargo.

Número publicado el 20 de diciembre de 2011 URL: http://revistadigital.eae.fcs.ucr.ac.crl 
Revista Gestión de la Educación, Vol.1, N², pp.67-106, ISSN 2215-2288, julio-diciembre, 2011

En suma, una organización educativa unidocente gestionada de forma adecuada "mantiene viva la presencia de la institución en la comunidad, posicionándola como una organización confiable, responsable, necesaria, sana, dinámica, y de beneficio social (...)" (Alvarado y Maya, 2009, p. 120), a lo que se agrega la importancia que tiene el lograr que la comunidad confíe en la educación como una herramienta para mejorar la calidad de vida.

Debido a este rol protagónico, el maestro unidocente requiere de una cualidad multifacética, acompañada de una formación atinente y adecuada para llenar las carencias y expectativas de la comunidad a la cual le brinda el servicio. Se hace obligante pensar en el perfil requerido que se ajuste a las características, exigencias y condiciones de este tipo de escuela.

\section{La calidad de la educación}

Es un concepto ambiguo pues se utiliza para referirse a diversos aspectos de la educación que se asocian con eficiencia y rendimiento escolar. Este término tiene como particularidad, la multiplicidad de temas educativos implícitos que están abiertos a la discusión. Según Garbanzo (2007):

En los últimos debates sobre el concepto de la calidad educativa, es generalizado el carácter de multidimensionalidad en torno a su definición, así como su complejidad para operacionalizarlo y aproximarse a una definición; situación que se debe, en gran medida a su carácter subjetivo, lo cual ha provocado una infinidad de posiciones, según el ángulo desde el cual se mire y la visión de quienes lo analizan. (p. 12)

Número publicado el 20 de diciembre de 2011 URL: http://revistadigital.eae.fcs.ucr.ac.crl 


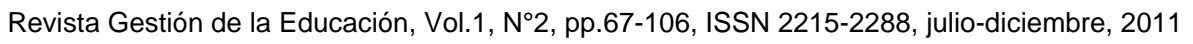

Al analizar la calidad de la educación se ha de tomar en cuenta dos funciones, primeramente la eficacia, entendida esta como el logro de objetivos educativos preestablecidos y luego la eficiencia conceptualizada y definida en la utilización de recursos tales como presupuesto para gasto e inversión en educación, condiciones óptimas de la infraestructura, del mobiliario y del equipo, la calidad de los materiales didácticos, el proceso de investigación educativa, la formación académica y la capacitación del personal docente y administrativo.

La calidad educativa está íntimamente ligada a la pertinencia, a la relevancia y equidad de educandos, su realidad tanto etaria como la satisfacción de sus necesidades básicas y su derecho a la educación, al respecto el Consejo Superior de Educación (2008), considera:

Concebimos como inherentes al concepto de calidad de la educación y como condiciones para su consecución los principios fundamentales de relevancia, pertinencia y equidad. Por ello, más que reiterar el derecho de todos a la educación, proclamamos como nuestro desafío la satisfacción del derecho de todas las personas a una educación de calidad.

Al reafirmar la educación de calidad como un derecho fundamental, establecemos como punto de partida el carácter universal de esta política educativa y su aspiración intrínsecamente inclusiva. (p. 5)

Conforme al Consejo Superior de Educación (2008) la calidad de la educación se define cuando se logra satisfacer una necesidad implícita o explícita que tiene el cliente, o bien el estudiante. Asimismo, la diversidad intercultural y las reseñas conceptuales generan una trama heterogénea y compleja de lo que podría ser el concepto de calidad de la educación aplicada a la realidad costarricense, la cual requiere un cambio de esquemas educativos y pedagógicos que transformen y se adapten a esa realidad, ese cambio para el Consejo Superior de Educación (2008): 
Revista Gestión de la Educación, Vol.1, º2, pp.67-106, ISSN 2215-2288, julio-diciembre, 2011

Implica una oferta educativa que atienda las necesidades y aspiraciones sociales en general, y en especial aquellas de los grupos más desfavorecidos. El respeto y la atención a la diversidad de los y las estudiantes, proporcionándoles oportunidades para aprender a lo largo de toda la vida, es condición de una educación de calidad para todos. Todos tienen derecho a una educación de calidad, que, partiendo de sus propias realidades, propicie el desarrollo de todo su potencial: estudiantes que aprenden a partir de estilos diferentes, con necesidades educativas especiales, talentosos, provenientes de distintos grupos étnicos, culturales, lingüísticos, que profesan credos religiosos diversos y cuyas condiciones sociales y económicas marcan sus ambientes de aprendizaje. (p. 8)

No obstante, la educación al ser una construcción social, que se concreta desde la dimensión pedagógica, social, cultural, económica y política tiene como indicadores determinantes el nivel de jerarquía y responsabilidad de quienes se encargan de la gestión administrativo-docente, por ello los maestros y las maestras perciben la calidad educativa desde la dimensión pedagógica y toman como indicadores básicos que el educando logre leer, escribir, realizar operaciones matemáticas y geométricas básicas; los padres de familia o encargados del alumno tienen como indicador lo tangible, lo concreto (edificio, mobiliario y equipo) y los tecnócratas toman como indicador la eficiencia a saber: índices de cobertura, datos de aplazados, reprobados, promovidos y otros.

\section{Formación profesional}

La formación profesional, impartida por las universidades tanto públicas como privadas del país, como parte de la formación universitaria para optar por el grado académico respectivo, se refleja en el diseño curricular que cada organización educativa propone. 
Revista Gestión de la Educación, Vol.1, №2, pp.67-106, ISSN 2215-2288, julio-diciembre, 2011

Según Quesada (2001), los diseños curriculares elaborados con la participación de diversos actores sociales, especialmente docentes, estudiantes, egresados y entes empleadores, ofrecen nuevas posibilidades en la construcción de conocimiento, donde la interdisciplinariedad, el autoaprendizaje, la toma de decisiones, entre otros, se tornan en aspectos relevantes de esa formación.

El currículo se debe concebir como el conjunto de las actividades de aprendizaje, es decir, los logros que alcanza el estudiante en función de los objetivos de la educación. En ese sentido, se refiere a una serie de elementos formales, actitudes, valores y creencias (de Alba, 1994), que favorecen y promueven la formación personal y profesional del estudiante para alcanzar un perfil ideal de graduado.

"El perfil del graduado define el conjunto de competencias que debe poseer el egresado al finalizar la carrera" (Quesada, 2001, p. 95). Es así, como este perfil atiende aspectos fundamentales, tales como la relación universidad-sociedad, es decir, la relaciónentre las necesidades sociales y la formación universitaria del estudiante, así como la adquisición de competencias esenciales para el desempeño profesional.

El término competencia se refiere a la formación de capacidades y disponibilidades personales, tanto en sentido intelectual, como ético, social y afectivo; que harán del profesional una persona preparada para ejercer la profesión.

Los cursos ofrecidos, por determinada organización educativa, deben buscar cumplir con los objetivos de la carrera y satisfacer las necesidades de los futuros profesionales así como de sus demandas. Al respecto, Mialaret (1984), define la demanda de la formación académica como:

La emergencia en la conciencia del educado de una necesidad de aprendizaje y de una necesidad de educación (...) el acto de educación será una respuesta a las demandas explícitas o implícitas de los educados, al mismo tiempo que un esfuerzo de elucidación y de análisis de estas demandas. (p. 130) 
Revista Gestión de la Educación, Vol.1, №2, pp.67-106, ISSN 2215-2288, julio-diciembre, 2011

De esta forma, se debe trabajar en aras de una sana articulación, tanto con las necesidades de los educandos, como con las de la compleja y desafiante sociedad, solo así se podría pensar en una gestión de la educación pertinente desde su naturaleza y objeto de estudio.

\section{Capacitación profesional}

La capacitación profesional es una extensión de la formación que recibe el profesional en su formación universitaria, que se hace necesaria ante el constante cambio de la sociedad y sus contextos. "La capacitación es el proceso educativo de corto plazo, aplicado de manera sistemática y organizada, por medio del cual las personas adquieren conocimientos, desarrollan habilidades y competencias en función de objetivos definidos" (Chiavenato, 2007, p. 386). Explica el autor, que la capacitación entraña la transmisión de conocimientos específicos relativos al trabajo, actitudes frente a aspectos de la organización, de la tarea y del ambiente, así como desarrollo de habilidades y competencias.

En una definición más limitada, "la capacitación es el acto de aumentar el conocimiento y la pericia de un empleado para el desempeño de determinado puesto o trabajo" (Flippo, 1970, p.236). Al respecto, la capacitación además de ofrecer la posibilidad de mejorar el desempeño en un campo particular, también desarrolla una serie de competencias para responder con eficiencia en lo individual y organizacional ante los desafíos sociales en los que está inmersa la organización.

La evaluación del desempeño, observación, cuestionarios, entrevistas y otros son medios para detectar las necesidades de capacitación del personal de cualquier organización. Basado en la información brindada por los medios antes mencionados se podrá establecer un programa de capacitación, el cual deberá definir las tecnologías a utilizarse. La tecnología informática (TI), incluye: recursos audiovisuales, teleconferencias, comunicaciones electrónicas, correo electrónico, tecnología multimedia, y otros. 
Revista Gestión de la Educación, Vol.1, N², pp.67-106, ISSN 2215-2288, julio-diciembre, 2011

\section{Administración de la educación}

El fin de la administración de la educación es lograr una gestión pertinente en la obtención de resultados óptimos, antes, durante y al final del proceso educativo con todos los insumos que componen la organización. Y la meta de la gestión es la aplicación del conocimiento existente para operacionalizar los objetivos propuestos por la organización. Con respecto de la administración de la educación, Arroyo (2007), define la administración de la educación como:

(...) el proceso de formular, implementar y evaluar las decisiones interfuncionales que se generan en los subsistemas estratégico y operativo que permitirán, a las organizaciones encargadas de ofrecer el servicio educativo que demanda la sociedad, alcanzar sus objetivos y aproximarse al logro de su visión-misión. (p. 3)

Al igual que en la administración los clientes son el objetivo principal de toda producción, en el caso de la administración de la educación, los alumnos son los miembros de la comunidad estudiantil por quienes se lleva a cabo todo el proceso, se puede afirmar que son los "clientes directos de la educación" (Lepeley, 2003, p. 32), ya que son quienes reciben el beneficio del servicio educativo.

Es necesario recalcar el hecho de que las organizaciones educativas se encuentran en constante evolución, son entes de cambio que deben responder a las necesidades de la sociedad actual, cuyos currículos deben estar de acuerdo con las demandas sociales, lo que conlleva un trabajo exhaustivo por parte de los administradores de la educación, responsables del producto que el sistema educativo está generando. 
Revista Gestión de la Educación, Vol.1, №2, pp.67-106, ISSN 2215-2288, julio-diciembre, 2011

\section{Referente metodológico}

La investigación se centró en describir y analizar las necesidades de capacitación y formación académica de los profesionales unidocentes del Sistema Educativo Costarricense. Esta información se recopiló mediante un cuestionario adaptado para estos efectos. La investigación realizada se ubica dentro del enfoque cuantitativo, se considera de carácter descriptivo y con diseño no experimental.

El estudio se llevó a cabo en el año 2010 mediante la aplicación de un censo a los 1.270 profesionales unidocentes del Sistema Educativo Costarricense. Los cuestionarios una vez pasados por el proceso de convalidación fueron entregados a los directores regionales, quienes los hicieron llegar a los asesores supervisores y estos a los maestros unidocentes. Se recopilaron 860 cuestionarios debidamente completados.

El alcance de esta investigación es descriptivo, pues especificó las necesidades de formación y capacitación de los y las maestras unidocentes de las diferentes organizaciones educativas a nivel nacional, importante especificar -para efectos de esta investigación- que el aprendizaje se entiende como la formación profesional recibida en su formación universitaria. El estudio definió los indicadores en las demandas de formación profesional (grado académico universitario) y capacitación profesional requeridas por los maestros unidocentes.

La investigación comprendió dos ejes esenciales para la buena gestión de una organización educativa unidocente: la formación académica, la cual es la formación profesional universitaria y la capacitación profesional, referente a la adquisición de conocimientos especializados para el mejoramiento del desempeño profesional, los cuales ofrecen información sobre el perfil del profesional unidocente, por lo que se analizaron las ofertas de planes y programas de estudio que imparten las universidades, tanto públicas como privadas, para optar por un grado académico especializado (da) en el área de la educación unidocente. 
Revista Gestión de la Educación, Vol.1, N²2, pp.67-106, ISSN 2215-2288, julio-diciembre, 2011

\section{Población}

Por ser un estudio que tuvo como objetivo censar a todos los profesionales de las organizaciones educativas unidocentes del país, el ámbito de aplicación del censo fueron los 1.270 maestros unidocentes del Sistema Educativo Costarricense, según los datos del Departamento de Estadística del Ministerio de Educación Pública al 30 de junio de 2010. La taza de respuesta fue de un $67,7 \%$, tal y como se muestra en la siguiente tabla:

Tabla 1

Escuelas Unidocentes según formularios recibidos

\begin{tabular}{|c|c|c|c|}
\hline $\begin{array}{l}\text { Dirección Regional } \\
\text { de Educación }\end{array}$ & $\begin{array}{c}\text { Escuelas } \\
\text { unidocentes }\end{array}$ & $\begin{array}{l}\text { Formularios } \\
\text { recibidos }\end{array}$ & $\begin{array}{l}\text { Porcentaje } \\
\text { de respuesta }\end{array}$ \\
\hline Aguirre & 47 & 43 & $91.49 \%$ \\
\hline Alajuela & 12 & - & $0.00 \%$ \\
\hline Cañas & 57 & - & $0.00 \%$ \\
\hline Cartago & 13 & - & $0.00 \%$ \\
\hline Coto & 120 & 114 & $95.00 \%$ \\
\hline Desamparados & 34 & 18 & $52.94 \%$ \\
\hline Grande de Térraba & 136 & 119 & $87.50 \%$ \\
\hline Guápiles & 41 & - & $0.00 \%$ \\
\hline Heredia & 4 & 4 & $100.00 \%$ \\
\hline Liberia & 30 & 27 & $90.00 \%$ \\
\hline Limón & 63 & 25 & $39.68 \%$ \\
\hline Los Santos & 31 & - & $0.00 \%$ \\
\hline Nicoya & 105 & 98 & $93.33 \%$ \\
\hline Occidente & 29 & - & $0.00 \%$ \\
\hline Pérez Zeledón & 72 & - & $0.00 \%$ \\
\hline Puntarenas - Peninsular & 94 & 88 & $93.62 \%$ \\
\hline Puriscal & 63 & 49 & $77.78 \%$ \\
\hline San Carlos - Zona Norte-Norte & 154 & 141 & $91.56 \%$ \\
\hline San José-Central & - & - & $0.00 \%$ \\
\hline San José-Norte & 1 & 1 & $100.00 \%$ \\
\hline San José-Sur-Oeste & 1 & 1 & $100.00 \%$ \\
\hline Santa Cruz & 26 & 26 & $100.00 \%$ \\
\hline Sarapiquí & 31 & 28 & $90.32 \%$ \\
\hline Turrialba - Sulá & 106 & 78 & $73.58 \%$ \\
\hline TOTAL & 1,270 & 860 & $67.72 \%$ \\
\hline
\end{tabular}

Fuente: Cuestionario aplicado a los maestros unidocentes del Sistema Educativo Costarricense, 2010.

Número publicado el 20 de diciembre de 2011 URL: http://revistadigital.eae.fcs.ucr.ac.crl 
Revista Gestión de la Educación, Vol.1, №2, pp.67-106, ISSN 2215-2288, julio-diciembre, 2011

Para el logro de los objetivos establecidos en la investigación, se utilizó la técnica cuantitativa del cuestionario. Es importante indicar que el cuestionario empleado es una adaptación del usado en la investigación "Necesidades profesionales de administración de la educación según las demandas del siglo XXI", realizada en el año 2009 en la Escuela de Administración Educativa de la Universidad de Costa Rica.

\section{Sistematización y análisis de la información}

El análisis se sustenta en los resultados obtenidos en la investigación, por medio de la aplicación de una encuesta dirigida a cada una de las organizaciones educativas unidocentes pertenecientes a las 27 Direcciones Regionales de Educación. Dicho análisis responde a una tasa de respuesta del $67.72 \%$ (860 cuestionarios recuperados de un total de 1.270).

Es importante aclarar que el cuestionario de la encuesta fue distribuido en un momento donde el sistema educativo se reorganizó en 27 nuevas Direcciones Regionales de Educación; sin embargo, para efectos de este estudio, se trabajó la estructura anterior en la que se contaba con 24 Direcciones Regionales de Educación, lo que se evidencia en el caso de las Direcciones Regionales de Educación de Puntarenas y San Carlos en donde la diferencia entre cuestionarios recibidos y cantidad de organizaciones educativas unidocentes no es proporcional; de igual forma no se cuenta con ninguna información de las Direcciones Regionales de Educación Peninsular y Sulá (cuestionarios incluidos en los datos ofrecidos por la Dirección Regional de Puntarenas) así como la baja participación de la Dirección Regional de Educación de la Zona Norte- Norte (cuestionarios incluidos en los datos ofrecidos en la Dirección Regional de Educación de San Carlos).

La tasa de respuesta fue absoluta en las Direcciones Regionales de Educación: Heredia, San José-Norte, San José-Sur-Oeste y Santa Cruz. También, es importante mencionar que hubo Direcciones Regionales de Educación de las cuales no se obtuvo tasa de respuesta alguna, a saber: Alajuela, Cañas, Cartago, Guápiles, Los Santos, Occidente y Pérez Zeledón. 
Revista Gestión de la Educación, Vol.1, №2, pp.67-106, ISSN 2215-2288, julio-diciembre, 2011

De los 860 cuestionarios devueltos (67.72\%), un 42.3\% (364 participantes) corresponde a la provincia de Puntarenas, un 17.6\% (151 participantes) a la provincia de Guanacaste, un 16.4\% (141 participantes) a la provincia de Alajuela, un 9.1\% (78 participantes) a la provincia de Cartago, un 8\% (69 participantes) a la provincia de San José, un 3.7\% (32 participantes) a la provincia de Heredia y un 2.9\% (25 participantes) a la provincia de Limón.

\section{Formación académica que tienen los maestros unidocentes de las Direcciones Regionales de Educación del Sistema Educativo Costarricense}

La formación académica es considerada como la recibida por los educadores y las educadoras en su formación universitaria, en la cual obtuvieron el grado académico universitario. Al consultar a los sujetos participantes del estudio con respecto de la formación académica se encontró que un $47.9 \%$ de los encuestados posee el grado académico de licenciado, un 29\% bachiller, un 13.5\% posee una maestría, un $8.6 \%$ obtuvo un profesorado y un $1 \%$ es aspirante.

Los licenciados dominan en las organizaciones educativas unidocentes, se evidencia el interés que existe en la población por continuar los estudios y obtener un grado más especializado en su formación. Este interés debería aprovecharse por los centros de educación superior, para ofrecer en sus planes de estudio ofertas llamativas que satisfagan las necesidades contextuales y demandas actuales de la modalidad unidocente.

Si en las universidades se presentara la especialización en la gestión de organizaciones educativas unidocentes, el $47.90 \%$ de licenciados probablemente habría optado por recibir esta formación, lo que supone que hay un mercado desatendido y en potencia de aceptar una educación en esta modalidad. 


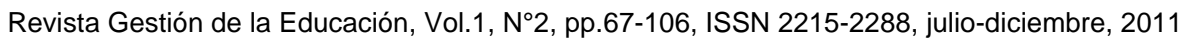

En lo que se refiere al grado académico de bachillerato universitario, se logró determinar que de estos profesionales un $91.8 \%$ obtuvo su Bachillerato en Educación Primaria, un 4.2\% en Ciencias de la Educación con Énfasis en Administración Educativa, un $1.5 \%$ en la Enseñanza de las Ciencias Naturales, un $0.7 \%$ en Educación Preescolar, otro 0.6\% en Educación Rural en I y II Ciclo, un 0.4\% Educación Primaria con Énfasis en Educación Indígena, un $0.3 \%$ en la Enseñanza de los Estudios Sociales, un $0.1 \%$ en Orientación, otro 0.1\% en Enseñanza del Inglés y 0.1\% en Educación Especial.

Urge fortalecer los programas educativos para que las demandas en la formación unidocente se vean satisfechas y el profesional se sienta capacitado para ejercer su labor de frente a los desafíos que la sociedad le plantea. Este fortalecimiento debe llevarse a cabo tanto en universidades públicas como privadas, cabe destacar que la Universidad de Costa Rica (pionera en educación nacional) y la Universidad Estatal a Distancia no ofrecen actualmente formación en unidocencia. Ambas universidades ofrecen sedes a lo largo del territorio nacional pero ninguna atiende la demanda. Si la población está haciendo el esfuerzo por formarse en centros privados y trasladarse a la capital para estudiar, mucho más sería la asistencia a los centros superiores públicos.

\section{Capacitación profesional recibida por los (as) maestros (as) unidocentes de las Direcciones Regionales de Educación del Sistema Educativo Costarricense}

La capacitación profesional son los conocimientos especializados que adquiere el educador y la educadora para el ejercicio de su desempeño profesional, por lo general son ofrecidos por el mismo Ministerio de Educación Pública o por instituciones especializadas en este campo. Un $72 \%$ de los maestros encuestados manifestó no haber recibido algún tipo de capacitación o cursos para unidocentes, mientras que un total de 28\% manifestó haber sido capacitado en su formación como maestro unidocente. 
Revista Gestión de la Educación, Vol.1, №2, pp.67-106, ISSN 2215-2288, julio-diciembre, 2011

El 28\% de los docentes que señaló haber recibido capacitación demuestra interés en seguir capacitándose. Actualmente, el MEP cuenta con dos dependencias capacitadoras: el Instituto de Desarrollo Profesional Uladislao Gámez Solano y el Departamento de Asesoría Pedagógica de cada Dirección Regional. Ambas dependencias fueron creadas con el fin de vigilar la formación profesional del personal docente en servicio, ofreciéndoles las herramientas necesarias para el mejoramiento de su desempeño y promoviendo un servicio educativo de calidad con un claro compromiso social.

Según los datos obtenidos, persiste un vacío entre la asistencia de los maestros unidocentes y las capacitaciones que ofrece el MEP (72\%); porcentaje considerable acorde con la inversión que realiza el Ministerio de Educación Pública en el fortalecimiento de los conocimientos del personal docente en servicio, por lo que se podría observar que la propaganda de las capacitaciones del MEP no llega a los maestros unidocentes, por ende, como se describe en el artículo cuatro de la Ley $\mathrm{N}^{\circ} 8697$, debe ser el maestro unidocente objeto de estudio para el mejoramiento de la calidad de la educación en las distintas organizaciones educativas.

No obstante, existe un $28 \%$ de docentes capacitados, individuos que buscan la manera de mejorar sus expectativas profesionales, por lo que las universidades públicas y privadas, en conjunto con el Ministerio de Educación Pública, deberían fortalecer las capacitaciones en materia unidocente, lo anterior tomando en cuenta planteamientos expuestos sobre la necesidad de la formación permanente, como lo expone Castells (1998):

Se calcula, que en estos momentos, una persona que empiece su vida profesional ahora, a lo largo de la vida cambiará, no de puesto de trabajo, sino de profesión, más o menos cuatro veces. Lo cual quiere decir que aquellas personas que sean capaces de redefinir lo que tienen que hacer, volver a aprender, volver a entrar en saber cómo hacer las nuevas tareas, nunca se quedarán obsoletas. (p. 4) 


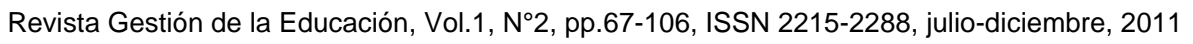

Considerando lo expuesto por Castells (1998), el maestro unidocente debe expandir sus conocimientos y mejorar sus habilidades específicas a la labor que realiza; esta iniciativa debe ser intrínseca y no nacer como una necesidad externa.

El 28\% que brindó respuesta, indicó haber recibido algún tipo de capacitación en su desempeño laboral, manifestó que el Ministerio de Educación Pública ocupa la primera posición con un $26.8 \%$ en capacitaciones, seguida por la Universidad Nacional con un $25.4 \%$, luego por las mismas organizaciones educativas unidocentes con un $10 \%$, capacitaciones ofrecidas por otras instituciones con un 8.6\%, la Universidad de Costa Rica con un 8.6\%, la Fundación Omar Dengo con un 4.3\%. Si se observa detenidamente la tabla anterior, universidades que forman maestros unidocentes como la Universidad Florencio del Castillo, no brindan seguimiento profesional con cursos que actualicen los conocimientos. Mientras un $72 \%$ manifestó no haber realizado ningún tipo de capacitación.

Según la información brindada por los participantes del estudio, temas específicos a las demandas en materia de administración en organizaciones educativas unidocentes se encuentran: 1. Gestión de organizaciones educativas unidocentes (10.1\%); 2. Administración de la educación (3.7\%); 3. Educación rural (2.6\%); 4. Planeamiento, Administración (1.1\%); 5. Planeamiento Curricular Unidocente (0.5\%).

La cantidad de contenidos correspondiente al área unidocente es relativamente poca, además, las personas capacitadas en dichos contenidos representan un porcentaje bajo por lo que se considera que a las entidades educativas responsables en realizar capacitaciones, les falta conocimiento de las necesidades de las organizaciones educativas unidocentes. EI MEP y las universidades, en primera instancia, podrían facilitar los espacios correspondientes para la preparación del personal unidocente en las áreas que más lo requieren. 


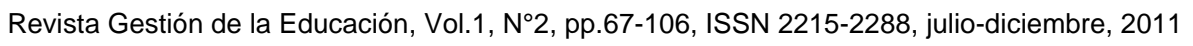

Es primordial que el fortalecimiento de los contenidos de los cursos que ofrecen las diferentes entidades estatales, debe ser especializado y focalizado en los contextos de las organizaciones educativas unidocentes, con el fin de solventar sus necesidades más inmediatas. Un acercamiento a la realidad de las organizaciones educativas unidocentes es fundamental para determinar el tipo de ayuda que se ha de brindar, y no dejar de lado su idiosincrasia como institución. Se debe tomar en cuenta, que a pesar de ser una organización educativa costarricense, sus características la hacen única de todas las demás. Es así como, a modo de ejemplo, no será funcional una capacitación en informática cuando la organización educativa carezca del equipo básico.

\section{Indicadores en las demandas de la formación académica de los maestros unidocentes para el pertinente desempeño laboral que requiere el Sistema Educativo Costarricense}

El $90.4 \%$ de los participantes posee una formación académica universitaria completa, lo que permite determinar con mayor precisión las áreas curriculares en las que estos docentes consideran necesaria una formación académica actualizada que responda a las necesidades de la población con la que se labora en una organización educativa unidocente.

Resulta oportuno señalar que dentro de los planes de estudio actuales de las universidades formadoras, ninguno incluye contenidos curriculares como legislación, políticas educativas o liderazgo, temáticas importantes en la gestión de una organización educativa unidocente.

Por otra parte, es importante enfatizar que el $84 \%$ de los encuestados obtuvo su grado académico más alto entre los años 1999 y 2010, lo que permite establecer un rango de 11 años durante los cuales se formó una cantidad considerable de los actuales maestros de organizaciones educativas unidocentes. 
Revista Gestión de la Educación, Vol.1, №2, pp.67-106, ISSN 2215-2288, julio-diciembre, 2011

Al establecerse un rango de 11 años, dentro del cual el 8\% obtuvo su grado académico más alto en el año 2005 , seguido de un $7.7 \%$ en el año 2009 , de un $7.2 \%$ en el 2007 , de un $7.2 \%$ en el 2008 y de un $7 \%$ en el 2006 , lo que corresponde a un $43.6 \%$ de la población encuestada, se puede considerar que las necesidades (en términos de formación académica) expresadas por los maestros unidocentes, responden a vacíos existentes en los actuales planes de estudio, por lo que es importante recordar que la oferta curricular “(...) tiene como propósito atender de modo eficiente las demandas y necesidades de los estudiantes en relación con sus planes de estudio" (Quesada, 2001, p. 137).

Al revisar los actuales planes de estudio de las universidades formadoras, en nueve de las 14 universidades privadas, y en dos de las cuatro universidades estatales se ofrece uno o dos cursos de administración de la educación, y únicamente dos universidades privadas ofrecen un curso relacionado con la educación rural. Por su parte, la Universidad Nacional es la única institución de enseñanza superior en la cual se ofrece una carrera en educación rural; sin embargo, del total de encuestados que respondió únicamente un $0.6 \%$ son egresados de este centro de estudios superiores.

Lo anterior confirma que una cantidad considerable de los maestros que se encuentran laborando en una organización educativa unidocente carecen de formación en educación rural específicamente en multigrado y, además, poseen conocimientos básicos en gestión de una organización unidocente, lo que no responde a lo que representa la misión de estas escuelas, es decir, el ser "la herramienta para promover la equidad en el campo educativo (...) garantizando la igualdad de oportunidades (...)" (Alvarado y Maya, 2009. p. 12), ya que para lograr promover equidad y garantizar igualdad es necesario que el responsable de dicha labor, cuente con las bases académicas necesarias para el buen desarrollo de cada una de las tareas ya establecidas.

El $78.2 \%$ de los informantes opinó sobre probables acciones a considerar para dar y ejecutar posibles soluciones en busca de una gestión eficiente de las organizaciones educativas unidocentes, al respecto se obtuvo la siguiente información: 
Revista Gestión de la Educación, Vol.1, N², pp.67-106, ISSN 2215-2288, julio-diciembre, 2011

- 23\% respondió que una formación especializada en el manejo de un centro unidocente es indispensable.

- $19.7 \%$ opina que los programas y los contenidos deben ser actualizados.

- 13.4\% considera que se debe ofrecer, además de la práctica docente habitual, práctica docente en una organización educativa unidocente.

- $12.2 \%$ apunta la necesidad de ofrecer cursos y prácticas especializadas en multigrado, por otra parte.

- $2.1 \%$ señala la importancia de que las universidades cuenten con docentes con experiencia en unidocencia.

- 7.3\% considera que se debe mejorar y actualizar la formación ofrecida a los estudiantes universitarios.

- $11.40 \%$ apunta la necesidad de ofrecer cursos de actualización y complementario para los maestros de organizaciones educativas unidocentes.

Es evidente, que para los maestros unidocentes, la formación académica recibida ha sido incompleta, ya que no ha tomado en cuenta el factor multigrado, ni la especificidad de una organización educativa unidocente.

Al preguntar a los encuestados si estarían dispuestos a matricularse en la Universidad de Costa Rica en una licenciatura en el campo de la gestión de organizaciones educativas unidocentes, un $77.4 \%$ contestó que sí, un $13.8 \%$ que no y un 8.8\% no respondió, lo que refleja el interés de los maestros unidocentes en adquirir las herramientas que les permitan llevar a cabo una gestión de la organización que responda a las demandas de una sociedad cada vez más exigente.

Número publicado el 20 de diciembre de 2011 URL: http://revistadigital.eae.fcs.ucr.ac.crl 
Revista Gestión de la Educación, Vol.1, №2, pp.67-106, ISSN 2215-2288, julio-diciembre, 2011

\section{Indicadores en las demandas de la capacitación de los (as) maestros (as) unidocentes para su desempeño laboral que requiere el sistema educativo costarricense}

A criterio de los informantes, y sobre las posibles soluciones que el Ministerio de Educación Pública debería considerar para su ejecución, un 17.3\% indica como una necesidad la capacitación; no obstante, un 82.7\% consideró otras acciones como necesarias, lo que demuestra que los maestros unidocentes no priorizan la importancia de la actualización de conocimientos como una condición en el desempeño laboral. Por otra parte, el hecho de que se observe que un bajo porcentaje de los maestros de organizaciones educativas unidocentes, participe de las capacitaciones ofrecidas por distintas organizaciones, evidencia que muchos vacíos curriculares de su formación académica siguen sin encontrar respuestas, más aún, en el caso de cursos o talleres que capacitan en la innovación, tales como los cursos de informática o adecuaciones curriculares, así como la capacitación en materia de gestión de la educación.

Las principales instituciones que capacitan a los maestros de organizaciones educativas unidocentes son las organizaciones públicas, en donde el Ministerio de Educación Pública es el principal ente capacitador con un porcentaje de $26.8 \%$, seguido por las universidades: la Universidad Nacional (UNA) y la Universidad de Costa Rica (UCR) con porcentajes de $25.4 \%$ y $10 \%$ respectivamente (cabe resaltar que no se indicó en qué campo) dado que dentro de sus políticas están las de capacitar y mejorar el desempeño de los profesionales en educación.

Número publicado el 20 de diciembre de 2011 URL: http://revistadigital.eae.fcs.ucr.ac.crl 


\section{Gráfico 1}

Necesidades que demandan los maestros unidocentes en su formación profesional

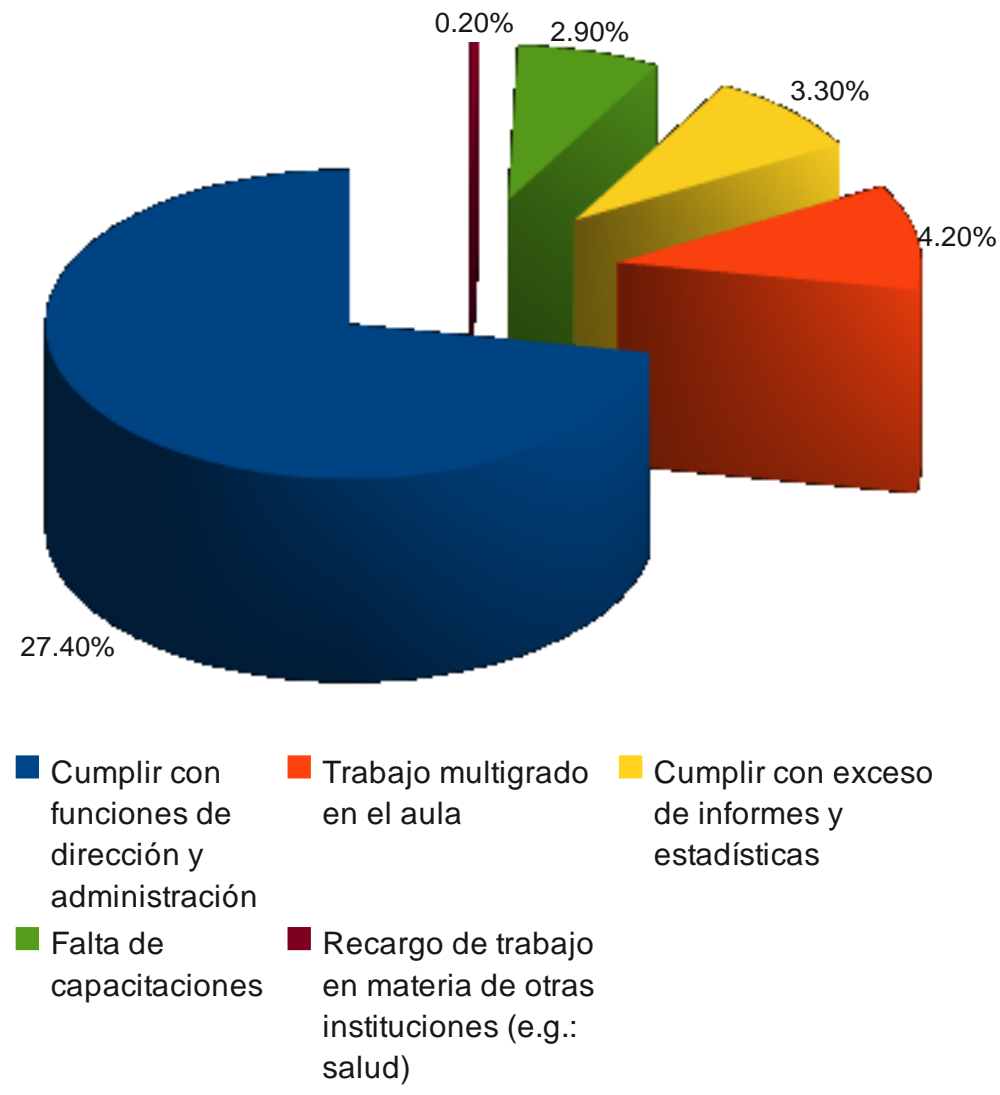

Fuente: Cuestionario aplicado a los maestros unidocentes del Sistema Educativo Costarricense, 2010.

Como se aprecia en el gráfico 1, los cursos de actualización y complementación para maestros de organizaciones educativas unidocentes representan el $11.4 \%$, lo que se puede relacionar con algunos de los obstáculos que ellos identificaron, como el cumplir con todas las tareas (administrativas y de dirección) que le son asignadas (27.4\%) y cumplir con informes y estadísticas (3.3\%) ya que el problema radica en la falta de preparación, por lo que las tareas se convierten en situaciones inmanejables para el docente.

Número publicado el 20 de diciembre de 2011 URL: http://revistadigital.eae.fcs.ucr.ac.crl 


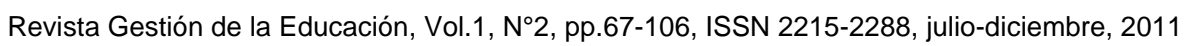

En tal sentido, se requiere que los diferentes entes capacitadores se preocupen por mejorar y actualizar las áreas temáticas objeto de capacitación, así como encontrar los medios necesarios para lograr llevar dichas capacitaciones a los maestros unidocentes.

Los cursos tutoriales $(0.8 \%)$, a distancia o virtuales, son una necesidad y una buena opción, ya que la lejanía de las organizaciones educativas unidocentes con respecto de los centros de enseñanza superior $u$ organismos capacitadores es un impedimento para docentes motivados en recibir cursos de actualización o de complementación de las formaciones académicas recibidas.

Como los encuestados lo indican, las áreas de administración (10.1\%) y manejo del aula multigrado (2.6\%) son las principales áreas en las que las capacitaciones deben ser constantes, ya que permitiría un mejor desempeño del docente. "Capacitación significa educación especializada. Comprende todas las actividades, que van desde adquirir una habilidad motora hasta proporcionar conocimientos técnicos, desarrollar habilidades administrativas y actitudes ante problemas sociales" (McGehee y Thayer, 1961, p. 138).

Un adecuado programa de capacitación permitirá dotar de herramientas al maestro de organizaciones educativas unidocentes, de forma que pueda cumplir con las metas institucionales, así como el que exista un clima organizacional generador de motivación, de forma tal, que se cumpla a cabalidad con las funciones de dirección y las de docencia.

\section{Soluciones para las necesidades de formación y capacitación de los (as) maestros (as) unidocente}

Al cuestionar a los maestros unidocentes sobre las posibles soluciones para satisfacer las necesidades de formación y capacitación desde la óptica del Ministerio de Educación Pública y las universidades formadoras, se obtuvo una serie de propuestas, las cuales se especifican respectivamente en los siguientes apartados.

Número publicado el 20 de diciembre de 2011 URL: http://revistadigital.eae.fcs.ucr.ac.crl 


\section{Propuestas de los maestros unidocentes al Ministerio de Educación Pública}

En el gráfico siguiente se observan las propuestas:

\section{Gráfico 2}

Propuesta de los maestros unidocentes al Ministerio de Educación Pública

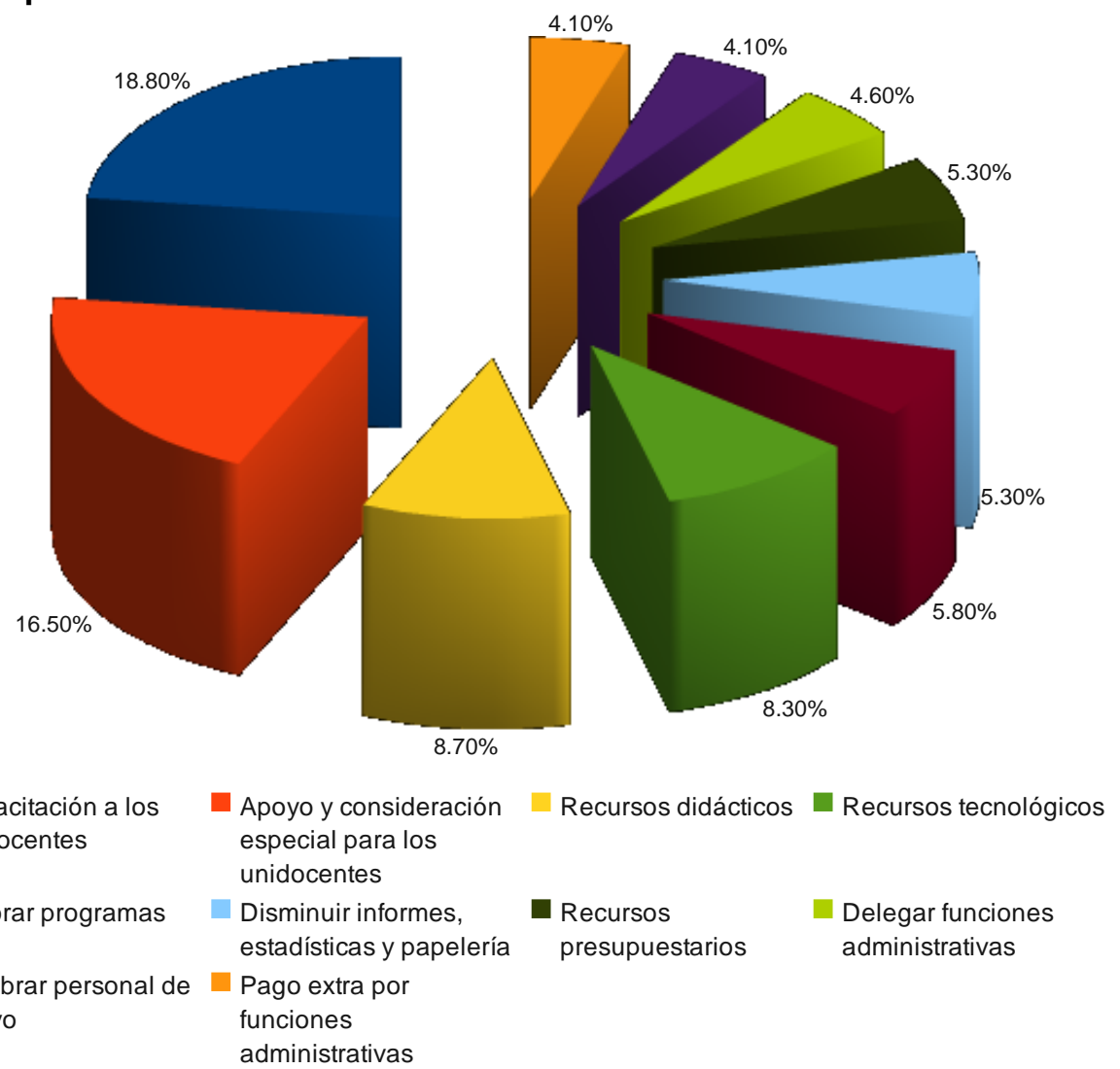

Fuente: Cuestionario aplicado a los maestros unidocentes del Sistema Educativo Costarricense, 2010. 
Revista Gestión de la Educación, Vol.1, №2, pp.67-106, ISSN 2215-2288, julio-diciembre, 2011

Como se nota en el gráfico anterior, el $18.8 \%$ de los docentes señaló la necesidad de recibir capacitación para realizar mejor su trabajo, lo cual demuestra interés personal de crecimiento profesional, adicionalmente un $8.3 \%$ de los encuestados indica la necesidad de adquirir equipo informático.

El $16.5 \%$ de los maestros unidocentes reclama del MEP apoyo y consideración, un trato especial para ellos, por las características propias de la organización educativa que administran, por el entorno geográfico donde se ubican y por ser radicalmente diferentes a otras organizaciones educativas de I y II ciclos.

En cuanto a los recursos didácticos el $8.7 \%$ de los maestros propone al MEP capacitarlos en el arte de enseñar pues consideran que los tiempos cambian. Para AnderEgg (1999) la formación del docente está ligada indisolublemente a dos cuestiones básicas de la práctica pedagógica: mejora de la calidad de la enseñanza y las condiciones de la implementación e innovación pedagógica.

El 5.8\% considera necesario que los programas de estudio respondan a la realidad de la organización educativa unidocente dentro de un marco de enseñanza multigrado. Una de las preocupaciones evidentes con un 5.3\% es en cuanto a la cantidad de informes estadísticos solicitados por las autoridades, lo que les demanda mucho tiempo pues, si no cuentan con herramientas tecnológicas, con programas informáticos y el conocimiento pertinente para este fin, el trabajo debe hacerse a mano, lo que perciben como un recargo de funciones.

También solicitan recursos presupuestarios acordes con las necesidades de la organización educativa, correspondiendo a un 5.3\%, dado que las partidas asignadas son insuficientes.

Los maestros unidocentes consideran apremiante delegar funciones administrativas, nombrar personal de apoyo y pago extra por estas funciones, las anteriores propuestas al MEP suman el 11.8\%, es visible el desconocimiento de lo que significa ser maestro unidocente, en este sentido es apremiante que los maestros de I y II ciclo conozcan la naturaleza del puesto antes de concursar o aceptar un nombramiento en una organización educativa unidocente. 


\section{Propuesta de los maestros unidocentes a las universidades formadoras}

En lo referente a la formación académica brindada por las universidades formadoras, tanto públicas como privadas, los maestros unidocentes detallan una serie de sugerencias, con la finalidad de responder a las demandas de una sociedad globalizada que exige una educación de calidad.

\section{Gráfico 3}

Propuestas de los maestros unidocentes a los Centros de Enseñanza Superior

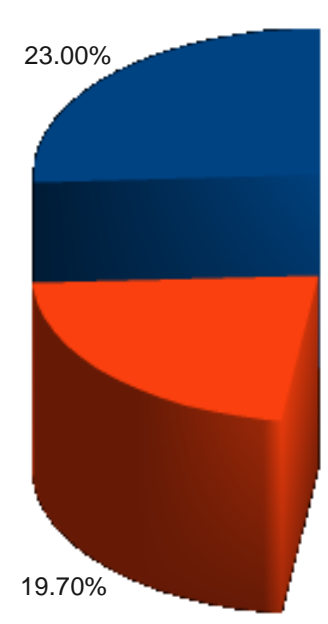

Formación especializada y más práctica para unidocentes

Cursos de actualización y complementación para unidocentes

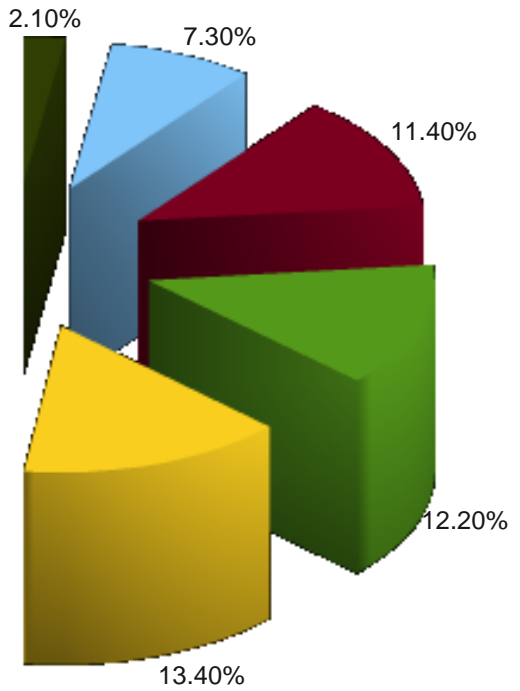

$\begin{array}{lll}\begin{array}{l}\text { Mejorar y actualizar } \\ \text { programas y } \\ \text { contenidos }\end{array} & \begin{array}{l}\text { Mayor práctica y } \\ \text { trabajo de campo } \\ \text { docente } \\ \text { (especialmente } \\ \text { unidocente) }\end{array} & \begin{array}{l}\text { Cursos y prácticas } \\ \text { especializadas en } \\ \text { multigrado }\end{array} \\ \begin{array}{ll}\text { Mejorar y actualizar } \\ \text { la formación de los }\end{array} & \begin{array}{l}\text { Profesores } \\ \text { universitarios } \\ \text { estudiantes }\end{array} & \begin{array}{l}\text { especialistas en } \\ \text { unidocencia }\end{array}\end{array}$

Fuente: Cuestionario aplicado a los maestros unidocentes del Sistema Educativo Costarricense, 2010. 
Revista Gestión de la Educación, Vol.1, º2, pp.67-106, ISSN 2215-2288, julio-diciembre, 2011

Una formación especializada en educación rural y más práctica docente representan el 23\%. Esta formación especializada se refiere a formación académica universitaria, en el área administrativa-docente, así como el uso de equipo informático y la Internet en búsqueda de realizar una labor eficaz y eficiente, por ejemplo, al poder interconectarse con la Dirección Regional de Educación respectiva y en general, con las organizaciones de la educación pública y demás entes relacionados, tal y como lo expresa Castells (2001):

La Internet es una red de redes de ordenadores capaces de comunicarse entre ellos (...), es un medio de comunicación, de interacción y de organización social (...), es el medio de comunicación y de relación esencial sobre el que se basa una nueva forma de sociedad que ya vivimos, que es lo que yo llamo la sociedad red. (p. 1)

Mejorar y actualizar programas y contenidos de los planes de estudio ofrecidos por las universidades formadoras es considerado por el $19.7 \%$ de los maestros unidocentes que respondió, una de las prioridades a solucionar. Otra de las soluciones planteadas y que representa el $13.4 \%$, se refiere a una mayor práctica y trabajo de campo docente (especialmente unidocente), esto implica cursos teórico-prácticos con el objetivo de emplear los conocimientos adquiridos.

Cursos y prácticas especializados en multigrado, es otra propuesta (12.2\%) de los maestros unidocentes, como solución al problema de tener que atender distintos niveles al mismo tiempo, lo cual dificulta el trabajo en el aula.

Un 11.4\% apunta la necesidad de asistir a cursos de actualización y complementación para unidocentes, lo que implica que al docente se le debe estar retroalimentando en formación administrativa-docente. 
Revista Gestión de la Educación, Vol.1, №2, pp.67-106, ISSN 2215-2288, julio-diciembre, 2011

\section{Uso que hacen los (as) maestros (as) unidocentes de la Internet}

La categoría de análisis de este objetivo es el uso que hacen los (as) maestros (as) unidocentes de las Tecnologías de la Información y de la Comunicación y la Internet y el indicador al cual se hace referencia es al acceso que tienen las organizaciones educativas unidocentes a las Tecnologías de la Información y de Comunicación, y a la Internet, de acuerdo con si tienen cobertura de Internet, equipo, mobiliario y conocimientos en informática.

El 85.4\% de los maestros unidocentes que respondió no tiene acceso a la Internet, de manera que, únicamente el restante $14.6 \%$ la posee. Se constata que el porcentaje de las organizaciones educativas unidocentes que tiene acceso a ella es ínfimo.

Del escaso porcentaje (14.6\%), el 34.7\% lo utiliza en un nivel alto, el $34.7 \%$ en un nivel medio y el 30.5\% en un nivel bajo, en relación con acciones propias de la gestión de la organización. Para revisar el correo electrónico personal, el 37.6\% lo utiliza en un alto nivel, el $33.6 \%$ lo utiliza en un nivel medio y el $28.8 \%$ en un nivel bajo. Para revisar el correo electrónico institucional el $40 \%$ le da un uso alto, el $24.2 \%$ lo usa en un nivel medio y el $35.8 \%$ en bajo nivel. En cuanto a la utilización como herramienta tecnológica en el aula, el $45.3 \%$ manifestó utilizarla en un alto nivel, el $21.9 \%$ en un nivel medio y el 32.8\% en un nivel bajo. Como medio de comunicación con los superiores jerárquicos el uso es un $38.3 \%$ alto, un $25.0 \%$ medio y un 36.7 bajo y como medio de actualización y/o capacitación, el 40.8\% manifestó hacer un alto uso de la Internet, un 38.4\% un uso medio y un $20.8 \%$ bajo. Tras analizar los datos anteriores, se desprende que estos profesionales de la educación no aprovechan esta herramienta tecnológica.

Mientras no haya una cobertura total a nivel nacional no puede usarse como un instrumento único de comunicación entre colegas, subalternos o jefes.

Se observa un desconocimiento, desinterés o indiferencia sobre la Internet porque muchos que la tienen no la usan. Es posible que un porcentaje considerable de maestros no haya descubierto la conveniencia y la oportunidad de agilizar la comunicación, y/o aprovechar la riqueza de la información para enriquecer el conocimiento personal y el de sus alumnos.

Número publicado el 20 de diciembre de 2011 URL: http://revistadigital.eae.fcs.ucr.ac.crl 


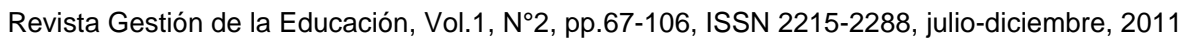

En cuanto a la pregunta del cuestionario "si estuviera en sus manos dar y ejecutar posibles soluciones para la gestión eficiente de las organizaciones educativas unidocentes, ¿qué haría usted desde la óptica del Ministerio de Educación Pública?, un 8.3\% manifiesta que dotaría a las organizaciones educativas de recursos tecnológicos, y un $0.2 \%$ implementaría informática en todas las escuelas. No se percibe interés en adquirir tecnología en informática. La misma pregunta anterior, solo que desde la óptica de las universidades, un $0.8 \%$ respondió que brindaría capacitaciones en informática para las organizaciones unidocentes. Tampoco considera importante la formación en este campo, falta estímulo para el aprendizaje de la informática.

Al preguntar a los encuestados sobre los principales obstáculos que enfrenta el maestro unidocente en su eficiente desempeño, el $4.4 \%$ se refirió a la falta de computadoras e informática y el $2.7 \%$ a la lejanía de los centros de informática con respecto de la organización educativa. Un bajo porcentaje cree en la importancia de la informática y considera un obstáculo no poder acceder a esta y a la Internet; otro pequeño porcentaje se lamenta de la distancia existente entre la escuela y el servicio de Internet de la zona.

Algunos apuntaron como elemento favorecedor para su eficiente desempeño el proyecto de la Fundación Omar Dengo con un $0.2 \%$. Este proyecto consiste en apoyar los procesos de aprendizaje, integrando las herramientas digitales a la cotidianidad del aula. El desconocimiento sobre el mérito de este es palpable, se hubiera esperado que una gran mayoría se inclinara por aprovecharlo. La tecnología informática contribuye a mejorar el proceso enseñanza aprendizaje, con programas adaptados al contexto social y cultural de la organización educativa. También, en la parte administrativa es una herramienta útil porque agiliza la gestión y permite un mejor aprovechamiento del tiempo. 
Revista Gestión de la Educación, Vol.1, N², pp.67-106, ISSN 2215-2288, julio-diciembre, 2011

Lamentablemente, "el progreso tecnológico sigue estando lejos del alcance de los pobres" (PNUD, 1999, p. 68). La brecha de la desigualdad se está haciendo cada vez más profunda, las diferencias entre el sector urbano y el rural persisten, esta situación se debe a la pobreza de muchas familias, a los problemas de acceso a las zonas rurales, a la falta de infraestructura escolar, a las limitaciones de conectividad en los hogares y en lasorganizaciones educativas rurales. Como lo expone De Alba y García (2003), mientras subsistan estas dificultades el servicio de la Internet se postergará indefinidamente:

(...) desde la perspectiva educativa nos interesa destacar, en todo caso, una fundamental: la desigualdad impregna todos los rasgos de la nueva realidad global; de tal forma que el mundo del siglo XXI se nos presenta como profundamente desigual, adquiere unos perfiles peculiares que conviene tener en cuenta al reflexionar sobre un modelo de educación deseable. (p. 86)

A pesar de los esfuerzos de la Nación es posible que muchas zonas no puedan impregnarse de los avances tecnológicos. Es importante destacar que la cantidad de niños de las organizaciones escolares unidocentes oscila entre uno y treinta, además hay que tomar en consideración lo fluctuante de esta población. 
Revista Gestión de la Educación, Vol.1, N², pp.67-106, ISSN 2215-2288, julio-diciembre, 2011

\section{Conclusiones}

Los profesionales encargados de las escuelas unidocentes, en su mayoría (49.9\%) poseen el grado académico universitario de licenciados; sin embargo, hay que tomar en cuenta que su formación profesional no es la misma, pues hay diversidad en las áreas en las cuales se han especializado y en el tipo de universidades.

- El $74.3 \%$ de los maestros unidocentes obtuvo el bachillerato universitario en educación primaria; no obstante, los planes de estudio no contemplan formación en el manejo y especificidad de un aula multigrado.

- El 19.2\% (porcentaje más alto) de las personas encuestadas recibió el grado más alto de estudio en la Universidad Florencio del Castillo (UCA).

- La Universidad Nacional (UNA) ofrece el grado de bachillerato en Educación Rural en I y II Ciclos. La Universidad de San José (USJ) y la Universidad Internacional San Isidro Labrador (UISIL) ofrecen un curso en su plan de estudios enfocado en la unidocencia. Los demás centros privados y públicos de educación superior no ofrecen formación en estas áreas.

- En los últimos años ha habido un incremento de profesionales optando por continuar sus estudios para obtener un grado más alto en el ámbito educativo, lo cual ha coincidido con la revaloración por títulos (incremento salarial) que ha otorgado en los últimos años el Ministerio de Educación Pública.

- El $90.4 \%$ de los participantes posee una formación universitaria académica completa, de los cuales un 29\% tiene el grado de bachillerato, $47.9 \%$ el grado de licenciatura y un $13.5 \%$ el posgrado de maestría, a pesar de esta realidad los participantes señalan la carencia en una formación específica en el campo unidocente. 
Revista Gestión de la Educación, Vol.1, №2, pp.67-106, ISSN 2215-2288, julio-diciembre, 2011

- Los planes de estudio de las universidades formadoras (tanto públicas como privadas) que ofertan la carrera de educación primaria, incluyen un único curso referente a la administración de la educación, únicamente la Universidad Metropolitana Castro Carazo ofrece dos cursos. Lo anterior justifica que un 23\% (de un 78.2\%) señale la necesidad de una formación académica específica en unidocencia así como práctica de campo, el 19.70\% de los maestros unidocentes (a partir de su experiencia laboral) apunte la necesidad de mejorar y actualizar los programas y contenidos de los planes de estudio, un $11.40 \%$ demande cursos de actualización y complementación para maestros unidocentes y un $12.20 \%$ solicite cursos y prácticas especializadas en multigrado.

- Los participantes (67.72\% del total de la población) opinaron que temáticas como epistemología y políticas educativas no son tan relevantes en la gestión de una organización educativa unidocente a diferencia de temáticas como planificación, diseño y evaluación de situaciones de aprendizaje, técnicas de evaluación y planeamiento didáctico, lo que evidencia una necesidad de preparación en multigrado dado que los planes de estudio de las universidades formadoras incluyen esas temáticas pero enfocadas al trabajo en un aula regular.

- Los maestros unidocentes participantes en el estudio solicitan una mejor preparación profesional, en materia de capacitación, sobre la gestión de organizaciones educativas unidocentes, pues entre sus necesidades destacan las labores de dirección y administración, entrega de estadísticas y trabajo en otras instituciones.

- Un $72 \%$ de los participantes del estudio no han recibido capacitación en la gestión unidocente, este dato es importante, pues pone en evidencia que un poco más de la mitad de la población encuestada nunca se ha capacitado en esta área. No obstante, está investigación no determinó los motivos de dicha falta de participación. 
Revista Gestión de la Educación, Vol.1, №2, pp.67-106, ISSN 2215-2288, julio-diciembre, 2011

- Las capacitaciones ya sea en línea, a distancia o presenciales, permiten a los maestros unidocentes adquirir y actualizar conocimientos necesarios para poder cumplir con éxito todas las tareas y objetivos institucionales; sin embargo, únicamente un $17.3 \%$ lo señalan como una acción transcendental en el desempeño laboral.

- El Ministerio de Educación Pública, la Universidad Nacional y la Universidad de Costa Rica son las instituciones indicadas por lo maestros unidocentes como las organizaciones que han brindado, en mayor porcentaje, capacitaciones.

- Los participantes solicitan cursos de capacitación específicos en unidocencia con la finalidad de dominar contenidos y herramientas para desarrollar habilidades y competencias que les permitan desempeñarse exitosamente, de forma tal que la acumulación y el exceso de trabajo (indicados por los participantes como obstáculos que enfrenta el maestro unidocente) sean vistos como parte de su gestión cotidiana.

Finalmente, tras las conclusiones analizadas con anterioridad se realza la importancia de la administración de la educación para un verdadero alcance de la calidad educativa. Es gracias a la administración que se logra una gestión pertinente en la obtención de resultados óptimos antes, durante y al final del proceso de la organización.

Las organizaciones educativas unidocentes requieren de una administración adecuada a sus demandas y a los servicios que ofrecen, por lo tanto, nace un gran interés por parte de los maestros unidocentes del país en fortalecer y enriquecer sus labores como directores, retomando la verdadera función de una organización en materia de planificación, dirección y control de los recursos que posee cada una, con el propósito de aprovechar e incrementar los insumos requeridos para el logro de objetivos.

Consecuentemente, el administrador de la educación debe conocer la cultura organizacional en la cual se encuentra para así concebir estrategias de negociación que le permitan una adecuada resolución de problemas. Para este fin, es indispensable el uso y el conocimiento de las TICs para un acercamiento más pertinente a las demandas del MEP y de la población a la que se le ofrece el servicio. 
Revista Gestión de la Educación, Vol.1, N², pp.67-106, ISSN 2215-2288, julio-diciembre, 2011

La comunicación entre las organizaciones educativas unidocentes y el MEP es indispensable para el mejoramiento del servicio que se ofrece, pues existe una población considerable que utiliza esta modalidad y su aporte a la sociedad es importante. Por lo tanto, es necesario brindar el apoyo pedagógico en contenidos curriculares en unidocencia para exaltar aún más la labor realizada por los maestros unidocentes del país. 
Revista Gestión de la Educación, Vol.1, N², pp.67-106, ISSN 2215-2288, julio-diciembre, 2011

\section{Referencias}

Alvarado, R. y Maya, A. (2009) La escuela unidocente: un reto y una oportunidad para la educación en la comunidad rural. Videoconferencia Colección Pedagógica de formador de formadores de educación básica o primaria. Recuperado de http://www.ceducar.org/ceducar/index.php?option=com jcalpro\&/temid=9\&extmod e=view\&extid=61

Arroyo, J. (2007). Gestión estratégica del personal en las organizaciones educativas. San José, Costa Rica: Editorial Universidad de Costa Rica.

Bernal, J. (1997). La escuela líder: una institución inteligente para mejorar la calidad de la educación. San José, Costa Rica: Ministerio de Educación Pública [MEP].

Castells, M. (Octubre-enero, 1998). Globalización, tecnología, trabajo, empleo y. Revista La factoría, $7 . \quad$ Recuperado de http://www.revistalafactoria.eu/restrict.php?tipo=articulo\&id=102

Castells, M. (2001). Internet y la sociedad red. Recuperado de http://tecnologiaedu.us.es/cuestionario/bibliovir/106.pdf

Chiavenato, I. (2005). Introducción a la teoría general de la administración. México: Editorial Mac Graw Hill.

Chiavenato, I. (2007). Administración de Recursos Humanos: El capital humano de las organizaciones. México: Editorial Mc Graw Hill.

Consejo Superior de Educación. (2008). El centro educativo de calidad como eje de la educación costarricense. Ministerio de Educación Pública. Recuperado de www.uned.ac.cr/educacion/.../un_centro_educativo_de_calidad.pdf

Correa de Molina, C. (2004). Gestión y evaluación de la calidad en la educación. Referentes generales para la acreditación. Bogotá, Colombia: Ed. Magisterio.

C.R. Servicio Civil (2004). Manual descriptivo de puestos docentes. Recuperado de http://www.educatico.ed.cr/Centros/TVLMHS/AreaAdmtva/Documentos\%20compar tidos/9\%20Manual\%20Descriptivo\%20de\%20Clases\%20de\%20Puestos\%20Doce $\underline{\text { ntes.pdf }}$

Número publicado el 20 de diciembre de 2011 URL: http://revistadigital.eae.fcs.ucr.ac.crl 
Revista Gestión de la Educación, Vol.1, №2, pp.67-106, ISSN 2215-2288, julio-diciembre, 2011

De Alba, A. (1994). Currículum: crisis, mito y perspectivas. México: Universidad Nacional Autónoma de México.

De Alba, N. y García, F. (Setiembre, 2003). La escuela ante las nuevas desigualdades. Cuadernos de Pedagogía, 327, 85-88.

Delgado, P. (2005). Eficacia y Calidad: una urgencia en los centros unidocentes de Costa Rica. Recuperado de www.eae.ucr.ac.cr/.../Ponencia.\%20Patricia\%20Delgado.doc

Flippo, E. (1971). Principios de gestión de personal. New York: Mc Graw Hill.

Garbanzo, G. (2007). Calidad y equidad de la educación superior pública. Aspectos por considerar en su interpretación. Revista Educación, 31 (2), 11-27. Universidad de Costa Rica, San José, Costa Rica. Recuperado de http://redalyc.uaemex.mx/pdf/440/44031202.pdf

Garbanzo, G. (2007). Retos actuales de la Administración Educativa en un mundo cambiante. Conferencia Escuela Administración Educativa, Universidad de Costa Rica, San José, Costa Rica. Recuperado de www.eae.ucr.ac.cr/Paginas.../Ponecia.Guiselle\%20Garbanzo.doc

International Organization for Standarization [ISO]. (2000). Norma Internacional ISO 9004. Recuperado de http://web.jet.es/amozarrain/iso 9004-2000.htm

Lepeley, M. (2003). Gestión y Calidad en Educación. Un modelo de evaluación. México: Editorial Mac Graw Hill.

McGehee, W. y Thayer, P.W. (1961). Training in Business and industry. New York, USA: Wiley Interscience.

Mialaret, G. (1984). Diccionario de Ciencias de la Educación. Barcelona, España: Oikostau.

Programa de las Naciones Unidas para el Desarrollo. (1999). La mundialización con rostro humano. Informe sobre desarrollo humano. Recuperado de http://hdr.undp.org/es/informes/mundial/idh1999/capitulos/espanol/

Quesada, M. E. (2001). El diseño curricular en los planes de estudio: aspectos teóricos y guía metodológica. Heredia, Costa Rica: Editorial Universidad Nacional. 